\title{
O ERRO NA EXPRESSÃO ORAL EM LÍNGUA ESTRANGEIRA: UM SIGNO QUE ANUNCIA APROPRIAÇÃO Janaína Nazzari GOMES ${ }^{1}$
}

RESUMO: O erro na expressão em língua estrangeira tem sido objeto de discussão em diversos campos que se ocupam da apropriação de línguas, dentre os quais, a Sociolinguística, a Linguística cognitiva e a Didática das línguas. Neste estudo, alternativamente, propomos uma interpretação sobre o erro na expressão em língua estrangeira com base nas reflexões de Ferdinand de Saussure (1995, 1996, 2002), cuja eloquência tem sido redescoberta após a publicação dos Escritos de Linguística Geral e dos manuscritos de Harvard e de Genebra. Saussure não tratou especificamente da apropriação de línguas estrangeiras, mas fornece-nos, ainda hoje, possíveis indícios para encontrar o que chama de linguístico: uma porção de som, prevista em uma comunidade linguística, a que é atribuída uma significação. Partindo da noção de língua-fala, elaboramos, então, uma reflexão que

\footnotetext{
${ }^{1}$ Mestranda em Análises textuais, enunciativas e discursivas pela Universidade Federal do Rio Grande do Sul e bolsista CAPES. Já ministrou, na mesma instituição de ensino superior, curso de fonética da língua francesa e, atualmente, trabalha com o ensino de francês para adultos e com atividades de sensibilização à diversidade da francofonia das Américas em formações universitárias de Letras em todo o Brasil. Também, é membro do Conselho de administração do organismo quebequense intitulado Centre de la francophonie des Amériques. Contato: janainafrances@gmail.com.
} 
tem no mecanismo analógico e no princípio do arbitrário do signo (a relação randômica entre porção de som e significação) os principais mecanismos linguísticos que estão presentes na apropriação de uma língua estrangeira. Tais mecanismos, precisamente, são responsáveis por permitirem e propiciarem a apropriação de uma língua não materna.

PALAVRAS-CHAVES: língua estrangeira; apropriação; analogia; Saussure.

\section{LA FAUTE DANS L'EXPRESSION EN LANGUE ETRANGERE: UN SIGNE ANNONCIATEUR D'APPROPRIATION}

RÉSUMÉ : La faute dans l'expression en langue étrangère a été l'objet de discussion dans divers champs qui traitent de l'appropriation des langues étrangères, dont la Sociolinguistique, la Linguistique cognitive et la Didactique des langues. Dans ce sens, alternativement, nous proposons une interprétation sur la faute dans l'expression en langue étrangère ayant comme support les réflexions de Ferdinand de Saussure, auteur dont l'éloquence est objet de découverte après la publication des Écrits de linguistique générale et des manuscrits de Genève et de Harvard. Saussure n'a pas spécifiquement traité de l'appropriation de langues étrangères, mais il nous fournit, encore aujourd'hui des possibles indices pour rejoindre ce qu'il appelle le linguistique : une portion de sonorité, prévue au sein d'une communauté linguistique, à laquelle une signification est attribuée. À partir de la notion de langue-parole, nous développons alors une réflexion qui a, dans le mécanisme analogique e dans le principe de l'arbitraire du signe (la relation établie sans motivation entre la portion de son et de signification), les principaux mécanismes linguistiques qui sont présents lors de l'appropriation d'une langue étrangère. Ce sont ces mécanismes qui permettent et facilitent l'appropriation d'une langue non maternelle.

MOTS-CLÉS : Langue étrangère, appropriation, analogie, Saussure.

\section{INTRODUÇÃO}

Muito já se estudou, tanto no campo da Linguística quanto no da Didática, sobre a influência da língua materna na apropriação ${ }^{2}$ de uma língua estrangeira assim como sobre a noção de erro nesse processo. A Didática de línguas desenvolveu numerosas pesquisas e manuais de ensino com o objetivo de propor um tratamen-

\footnotetext{
${ }^{2}$ Ao longo deste trabalho, utilizaremos o termo apropriação de línguas genericamente; ao final, explicitaremos os motivos pelos quais optamos pelo emprego preciso deste termo.
} 
to pedagógico cada vez mais adequado ao erro ${ }^{3}$. A Sociolinguística e a Linguística Cognitiva, por sua parte, sendo os principais campos da linguística a se debruçar sobre a temática do erro na apropriação de línguas, não só elaboraram construtos teóricos que buscassem explicar os erros nas produções - levando em conta, respectivamente, os contextos de interações e de significação - como também emprestaram muitas de suas reflexões à própria Didática das línguas 4.

No entanto, parece-nos que, o campo da Linguística ainda pouco explorou, justamente, as motivações primordialmente linguísticas daquilo que é considerado erro na expressão em uma língua outra que aquela que escutamos desde o ventre materno. Além disso, apesar de toda reflexão teórica, na sala de aula, o erro é frequentemente tomado como uma produção que deve ser proibida pelo professor no intuito de evitar que o estudante fossilize, nos termos da Didática de línguas (CUQ, 2003: 101), uma forma incorreta e passe a reproduzi-la sem cessar.

Mas o que seriam as "motivações primordialmente linguísticas" de que falamos anteriormente? Neste trabalho, adotamos os estudos empreendidos pelo linguista Ferdinand de Saussure, cujas reflexões, iniciadas com o Curso de Linguística Geral (1996), são, hoje, alvo de redescoberta, sobretudo, após a publicação dos Escritos de Linguística Geral (2002) e dos manuscritos de Havard e de Genebra (1995 e 2002, respectivamente). Assim, de acordo com o pensador suíço, o fato linguístico reside no momento em que uma porção de som encontra uma significação, formando um signo: "a única definição que dela [da unidade linguística] se pode dar é a seguinte: uma porção de sonoridade que, (...), é significante de um certo conceito" (Saussure, 2002: 130). Não se trata, portanto, de tratar somente da significação, que, segundo Saussure, é uma tarefa da Psicologia (1996: 14,16), nem somente da porção de som, tarefa da Fonologia (1996: 26). A Linguística se ocuparia - e vemos isso no início do Curso de Linguística Geral - de "procurar as forças que estão em jogo de maneira permanente e universal em todas as línguas" e de elencar "as leis gerais às quais podemos associar todos os fenômenos particulares da história” (1996: 13).

A pesquisa que empreendemos neste momento, portanto, tendo como objetivo geral a compreensão e a delimitação dos mecanismos linguísticos que estão em jogo na apropriação de uma língua não materna, e adentra, pois, na questão do erro para analisá-lo a partir de seu aspecto linguístico, isto é, a partir da relação entre porções de som e de sentido produzidas pelo falante de uma língua estrangeira, tal como é a noção de linguístico em Saussure. Uma consequência possível de nossa abordagem, como veremos na sequência, seria justamente um tratamento pedagógico alternativo daquilo que é considerado incorreto na expressão em língua estrangeira. Nós iremos, portanto, tentar compreender - através de deslo-

${ }^{3}$ Conforme, por exemplo, Larruy, M. M., L'interprétation de l'erreur, CLE International, 2003.

${ }^{4}$ Cientes das numerosas e complexas imbricações entre a Linguística Aplicada e a Didática de línguas, adotamos, neste trabalho, para fins de reflexão, as contribuições desta última, a Didática de línguas, e, sobretudo, as reflexões do livro Dictionnaire de didactique du français - langue étrangère et seconde (2003), o linguista, didático e ex-presidente da Federação internacional dos professores de francês, Jean-Pierre Cuq. 
camentos teóricos, já que Saussure não desenvolveu uma teoria sobre apropriação de línguas - o erro na expressão em língua estrangeira a partir dos conceitos saussurianos de língua-fala, de analogia e de arbitrário, apresentados, em Linguística moderna, em 1916, ano da publicação do Curso de Linguística Geral, obra que completa, em 2016, seu centenário.

Antes de iniciarmos o estudo que ora propomos, são necessárias, porém, algumas observações acerca do escopo teórico que adotamos para elaborar o presente artigo. Nesse sentido, em um primeiro momento, adentraremos brevemente na obra de Ferdinand de Saussure $(1995,1996,2002)$ e no tratamento a ela deferido por seus leitores. Em um segundo momento, de maneira mais incisiva e profunda, iniciaremos nossa reflexão sobre o que é considerado erro em língua estrangeira à luz da teoria saussuriana.

\section{DAS INTERPRETAÇÕES DA OBRA SAUSSURIANA}

A obra responsável pela fundação da Linguística foi também responsável por, aparentemente, excluir de seu objeto de estudo o conceito de fala, isolando-a da língua. Com efeito, no próprio Curso de Linguística Geral, parece haver uma cisão entre ambos os conceitos: enquanto a língua seria uma manifestação coletiva e virtual, completa somente com a reunião de todos os locutores de uma comunidade linguística, a fala seria um produto individual da capacidade de linguagem. Visto os critérios científicos da época exigirem objetos de estudos gerais e sem referências subjetivas, o linguista genebrino teria tomado somente a instância virtual como objeto por excelência da Linguística.

Uma pergunta que poderíamos nos fazer agora é: se Saussure trata somente da língua e se o erro acontece na fala, por que não utilizar referentes teóricos que privilegiem a instância da expressão ao invés da dimensão virtual? Ao estudamos o Curso, os Escritos de Linguística Geral e os manuscritos de Harvard e de Genebra - que, aliás, tratam, respectivamente, sobre fonética e sobre sonantes -, é possível vislumbrar um conceito de língua como instância complementar da fala, assim como, segundo o próprio Saussure, uma folha de papel, em que as duas partes frente e verso - não podem ser separadas. Dessarte, para tratar do erro a partir de uma perspectiva saussuriana, em um primeiro momento, é preciso ressituar teoricamente a relação língua-fala, para, em seguida, tomando os conceitos saussurianos de significante-significado, de arbitrário e de analogia, tentar compreender o mecanismo linguístico que permite e produz a forma tida como errônea e que, em última análise, é a expressão máxima do processo de apropriação.

Antes, no entanto, é preciso precisar nosso posicionamento acerca das fontes do pensamento saussuriano. O que podemos dizer da obra deixada por Saussure é que ela gera importantes controvérsias. De um lado, há o debate sobre a legitimidade do Curso: discute-se se ele faz ou não parte do pensamento saussuriano por 
ele não ter sido escrito diretamente por Saussure. De fato, o livro responsável pela fundação da disciplina da Linguística não fora escrito por Ferdinand de Saussure, mas por Charles Bally et Albert Secheaye, linguistas que reuniram notas de alunos participantes de três cursos sobre linguística geral, ministrados por Saussure, em Genebra, entre 1907 e 1911. Como podemos ler no prefácio dos editores do Curso de Linguística Geral, os próprios editores reconhecem a dificuldade da reunião das notas e da tentativa de reprodução do pensamento de Saussure:

Decidimo-nos por uma solução mais audaciosa, mas também, acreditamos, mais racional: tentar uma reconstituição, uma síntese, com base no terceiro curso, utilizando todos os materiais de que dispúnhamos, inclusive as notas pessoais de F. De Saussure. Tratava-se, pois, de uma recriação (...). (SAUSSURE, 1996: 3).

De outro lado, há a questão do que fora, durante muito tempo, difundido como sendo A (maiúsculo) teoria saussuriana: a separação entre língua e fala e as consequências epistemológicas e metodológicas que derivam disso.

$\mathrm{O}$ debate sobre as fontes saussurianas diz respeito basicamente à aceitação do conteúdo do Curso como pertencente ou não a Saussure. Simon Bouquet, o editor dos Escritos de Linguística Geral, na introdução da obra, caracteriza o curso pejorativamente como uma vulgata do pensamento de Saussure (Saussure, 2002: 12). Por outro lado, Claudine Normand, leitora consagrada de Saussure, toma o mesmo termo - vulgata - para assinalar a importância da popularização do Curso, empregando-o, portanto, de forma positiva (Normand, 2009: 21). Para nós, a diferença essencial entre o Curso e as outras fontes da obra de Saussure concerne à maneira pela qual o pensamento é transmitido: enquanto o Curso nos apresenta uma teoria mais fechada, com a adoção radical, por partes dos editores, de certos conceitos, como a separação de língua e fala, as demais fontes nos mostram um linguista refletindo sobre os fenômenos língua/fala e sobre a disciplina científica que considerava necessário criar. Além do mais, se atentarmos para a flutuação terminológica - um critério que não nos parece menor para a avaliação da pertinência de uma obra -, vemos que ela está presente tanto no Curso quanto nos demais escritos, o que de maneira alguma tira a coerência do conteúdo apresentado, apesar de, é claro, levantar questões que, em última análise, contribuem para compreender o processo reflexivo do autor.

O segundo debate de peso relacionado à obra saussuriana diz respeito à já mencionada separação entre os conceitos de língua e de fala. De fato, a cientificidade do fim do século XIX e início do século XX previa um objeto destacado do sujeito para que fosse possível isolá-lo teoricamente. É verdade que, já no começo do Curso, encontramos a separação de aspectos materiais da definição de língua: "as relações da Linguística com a fisiologia não são difíceis à compreender: trata- 
se de uma relação unilateral (...). O essencial da língua é estranho ao caráter fônico do signo" (SAUSSURE, 1996: 21). E eis que, apesar desta aparente definição tão purista do conceito de língua, o Curso apresenta toda uma seção e um apêndice que trata especificamente da Fonologia e que desenvolve a relação entre a língua e seu aspecto material, ou seja, o aspecto fônico.

De fato, no Curso, Saussure redefine o conceito de fonologia (considerada, em sua época, o estudo da fisiologia dos sons): diz que "é necessário delinear o sistema fonológico do idioma estudado, isto é, o quadro de sons de que [o linguista] se vale; [e que] cada língua (...) opera sobre um número determinado de fonemas bem diferenciados. Esse sistema é a única realidade que interessa ao linguista" (1996: 58). Assim, à definição de fonologia, que até então, considerava somente o aspecto fonatório do som, Saussure acrescenta o conceito de sistema, próprio à língua, o que parece apagar definitivamente a interpretação dicotômica que separa língua de fala.

Concebemos, pois, um conceito de língua-fala mais coerente com o fenômeno que representa: duas instâncias interligadas e interdependentes. Além disso, Saussure afirma que os fatores distintivos dos fonemas - essenciais para haja a possiblidade de conformação de um sistema linguístico - compõem o primeiro sistema de diferenciação de um idioma: "cada língua, (...) opera com um número determinado de fonemas bem diferenciados", que são "o que se pode imaginar de mais irredutível como elemento de sua estrutura” (SAUSSURE, 2002: 27).

Há, porém, ainda outros importantes aspectos que parecem comprovar nossa leitura acerca da imbricação entre língua e fala na teoria saussuriana: a noção de escuta, de efeito e de recorte de unidade. No Curso, Saussure diz que "é pela orelha que nós sabemos o que é um b, um t, etc." e que a escuta "é a base de toda a teoria" (1996: 64). Assim, além de ser um objeto abstrato, social e geral, segundo as palavras do próprio Curso, a língua é também representação, fala e escuta, já que, como acabamos de mencionar, só é possível encontrar as unidades que compõem o sistema pela orelha 5 .

Uma vez articulados, tais conceitos forjam uma noção de língua que conjuga uma materialidade atravessada pelo simbólico, quer dizer: no momento em que um som, produzido fisiologicamente, pelo aparelho fonador, tem valor em uma comunidade linguística, isto é, quando ele produz diferenças em um sistema, não mais se trata exclusivamente de som puro, mas, ao contrário, de um som que significa e que tem valor e, portanto, um som que representa, pela voz, uma unidade linguística. Com tal interpretação, é possível acessar os conceitos de língua-fala ${ }^{6}$. Acrescentaríamos, aqui, que, à noção de língua-fala, é possível associar as noções de significante e significado, que foram, inicialmente, chamados por Saussure de

\footnotetext{
${ }^{5}$ Para maior detalhamento desta temática consultar a dissertação "Quando falar e ouvir é apropriar-se: um estudo sobre apropriação de língua estrangeira à luz das contribuições de Ferdinand de Saussure", defendida na Universidade Federal do Rio Grande do Sul, de autoria de Janaína Nazzari Gomes (2016).

${ }^{6}$ (Note-se que Saussure utiliza o termo signo para chamar o que, posteriormente, em sua teoria, trata de significante.)
} 
imagem acústica e ideia. A noção de significante nos é, particularmente, interessante porque traduz a inter-relação entre as instâncias de língua e fala, já que o significante é, ao mesmo tempo, representação virtual, compondo, portanto, a língua, e materialidade fônica, fazendo, então, parte da fala, conforme podemos ver no excerto abaixo:

O dualismo reside na dualidade do fenômeno vocal como tal e do fenômeno vocal como signo1 - do fato físico (objetivo) e do fato físico-mental (subjetivo). (...) Há um primeiro domínio, interior, psíquico, onde existe o signo assim como a significação, um indissoluvelmente ligado ao outro; há um segundo, exterior, onde existe apenas o "signo" mas, nesse momento, o signo se reduz a uma sucessão de ondas sonoras que merece de nós apenas o nome de figura vocal. (SAUSSURE, 2002: 24).

É nessa relação constitutiva de abstrato - a língua como sistema dado - e de concreto - a fala - que o erro na expressão em língua estrangeira acontece, já que, ao que parece, o falante de um idioma estrangeiro comete um erro em relação ao que é esperado no sistema, isto é, na língua. Investigar os mecanismos linguísticos que possibilitam tal produção considerada incorreta nos parece, no mínimo, pertinente por poder, talvez, possibilitar novos olhares sobre o processo de apropriação de uma língua estrangeira e sua singularidade constitutiva.

\section{QUANDO FALAR É APROPRIAR-SE E QUANDO APROPRIAR-SE É A BUSCA PELO REGULAR}

Em geral, os primeiros contatos com uma língua estrangeira ocorrem através do concreto, ou seja, da fala ouvida ou lida. Já o erro aparece quando o falante produz formas não esperadas ou não usuais no sistema linguístico alvo: é um "écart par rapport à la représentation d'un fonctionnement normé, l'erreur linguistique a longtemps été liée en didactique des langues aux interférences de la langue maternelle et de la langue étrangère" . Nesse contexto, uma pergunta que poderíamos nos fazer diz respeito ao caráter dos erros produzidos: trata-se de dificuldades cognitivas, em que um falante não consegue compreender as demandas linguísticas da língua que busca dominar? Ou trata-se de dificuldades no aparelho fonador, em que, simplesmente, o falante é incapaz de produzir determinados sons? Nossa hipótese - e é aí que as contribuições saussurianas nos parecem mais

\footnotetext{
7 "uma distância em relação à representação de um funcionamento normativo, o erro linguístico tem estado ligado, em didática de línguas, às interferências da língua materna e da língua estrangeira" (CUQ,2003: 46).Tradução nossa
} 
produtivas - é que o que está em jogo no momento da produção de formas consideradas errôneas em língua estrangeira é a suposição de regularidades existentes, motivadas pelas formas já conhecidas do sistema linguístico materno.

De fato, parece ser uma tendência dos falantes a busca por regularidades através de formações analógicas. Saussure trata de tal fenômeno, ao citar falantes francófonos, que, conjugam o particípio passado do verbo mourir da mesma forma como conjugariam o verbo courir: se para courir, digo couru, para mourir, digo $\mathrm{mouru}^{8}$. Enquanto a forma, segundo a gramática normativa, seria mort. A regularidade da língua permite não somente que uma forma alternativa seja criada como também seja passível de ser compreendida por ouvintes francófonos.

Como citamos anteriormente, o que é considerado erro em língua estrangeira, além de ser criado com base em regularidades do próprio sistema linguístico, também pode ter como base linguística a língua materna. Assim, é preciso nos determos brevemente sobre este sistema, para, então, passarmos à análise de formas consideradas errôneas em línguas estrangeiras. A pergunta que caberia agora é: por que um falante recorreria à sua língua materna para produzir formas significantes em outras línguas? Ora, a língua materna é o primeiro sistema simbólico que introduz o mundo à criança. Salvo situações de bilinguismo ou ainda de multilinguismo, a primeira língua de um indivíduo chega a ter para o falante, quase um valor absoluto, em que a forma linguística parece designar perfeitamente a coisa do mundo, sem haver, por exemplo, espaço para outras formas de designações. Por exemplo, não raro, ao trabalharmos com o gênero das palavras em francês, estudantes lusófonos brasileiros queixam-se de que a palavra mar seja feminina e garagem seja masculina enquanto, em sua língua materna, é exatamente o contrário. A língua materna parece, pois, ter, um valor deveras fundante para o indivíduo e, além de ser a língua que mais utilizou em seu percurso de vida, é também a primeira língua que lhe permitiu ser e comunicar-se no mundo9. É, pois, com a intersecção constante entre sistema primeiro e estrangeiro que um falante lida ao tentar expressar-se em um novo sistema linguístico.

Nesse sentido, tomaremos como ilustração os dizeres de $\mathrm{MIC}^{10}$, estudados em GOMES (2011), levando em conta a utilização que o falante faz do passado composto em francês.

\footnotetext{
${ }^{8}$ Em português, mourir significa morrer e courir, correr.

${ }^{9}$ Para maior detalhamento sobre tal discussão, ler GOMES, J. N. O enunciador em língua estrangeira: uma constituição possível? Porto Alegre: Universidade Federal do Rio Grande do Sul, 2011. Trabalho de Conclusão de Curso.

${ }^{10} \mathrm{MIC}$ era, à época, estudante de francês de nível intermediário. Segundo a autora, os dados foram obtidos através de duas entrevistas dirigidas, que eram simulações da entrevista para imigração ao Québec, província do Canadá. As entrevistas completas, o contexto da produção dos dados e as etapas da pesquisa podem ser encontradas em GOMES, J. N. O enunciador em língua estrangeira: uma constituição possível? Porto Alegre: Universidade Federal do Rio Grande do Sul, 2011. Trabalho de Conclusão de Curso.
} 


\author{
Exemplo 1 \\ 13 JAN Où êtes-vous nés? \\ 14 MIC Je suis né à Maceió. \\ 15 JAN Et votre épouse? \\ 16 MIC Ééé... elle a née à Rio Grande do Sul. \\ 17 JAN Ok. Et dans quelle ville? \\ 18 MIC Elle née à [...] Ahh [...] Je ne me souviens pas, mais c'est une petite ville de \\ Rio Grande do Sul

\section{Exemplo 2} \\ 31 JAN Vous êtes mariés depuis quand? \\ 32 MIC Nous avons marié [...] Nous vivons ensemble beaucoup de temps. J'ai cinq \\ ans que je vive avec elle, nous vivons ensemble, mais nous fait la cerimônia é [...] un \\ an, deux ans plus ou moins [...] há un an, deux ans.
}

\title{
Exemplo 3
}

59 JAN Ah. OK Et [...] Ahm [...] Dans quelles entreprises vous avez travaillé ?

6o MIC J'ai commencé avec la programmation à Planetec et depuis un an j'ai [...] j'ai resté chez moi parce que [INC]... . Je ne souviens pas comment se dit en français.

Nesses três exemplos, vemos pelo menos, três utilizações diferentes do passé composé: seja na forma mais frequente e gramaticalmente correta - "je suis né" et “j'ai commencé" -; seja na forma em que há a utilização de um verbo auxiliar mas o auxiliar considerado incorreto segundo a gramática - "elle a née", "nous avons marié", "j'ai resté chez moi..."; seja com o apagamento total do auxiliar "Elle née à", "nous fait la cerimônia". Tais exemplos, apesar da aparente incongruência, parecem testemunhar a existência de um mecanismo linguístico pautando o dizer, afinal, se o falante conhece as estruturas que deve utilizar, por que as troca constantemente?

Com efeito, parece-nos que se trata do que Saussure chamou de procedimentos analógicos e que as fontes dessas analogias são, como já assinalamos anteriormente, tanto o idioma alvo quanto a língua materna. O que é importante notar, em um primeiro momento, é que em ambas as situações - tanto naquelas em que o falante utiliza um verbo auxiliar quanto naquelas em que não as utiliza -, o falante não criou formas ex nihilo, mas, ao contrário, procurou formas disponíveis em seu sistema linguístico. Tal constatação não nos parece menor: apesar das discrepâncias segundo a gramática tradicional, ao utilizar majoritariamente formas da língua alvo, o falante já se situa no sistema linguístico de que almeja apropriar-se. De fato, ele identifica - mesmo inconscientemente - as unidades significantes (as formas) que compõem cada uma das duas línguas (SAUSSURE, 2002: 159). Até 
mesmo quando o falante utiliza os verbos considerados incorretos do ponto de vista da gramática (com o verbo auxiliar avoir ${ }^{11}$ ), ele já está situado em um sistema que dita que o valor de um pretérito perfeito seja representado pela utilização de dois verbos - o primeiro, um auxiliar conjugado no presente e, o segundo, o verbo principal, na forma do particípio passado (caso das produções "je suis né", “j'ai commencé”, "elle a née”, "nous avons marié”, “j'ai resté chez moi”).

Notemos, no entanto, que, quando o falante produz a frase "nous fait la cerimônia”, ele deixa de lado a forma esperada em francês e adota uma forma mais parecida com aquela utilizada em sua língua materna, o português. Ele retira, portanto, o verbo auxiliar e utiliza uma forma semelhante à do passado de sua língua materna, o português. Não nos parece randômico tal procedimento: ao faltar-lhe a forma na língua estrangeira, o falante recorre ao sistema que primeiramente lhe permitiu comunicar-se no mundo. Sua presença não é, portanto, negociável e nem pode ser excluída do sistema linguístico de um falante.

Notemos que a constatação que acabamos de fazer não se refere somente a falantes de níveis iniciantes ou intermediários. Vejamos outro exemplo de diálogo, desta vez, com foco nos dizeres de JAN, professora da língua francesa, com inúmeras experiências em países francófonos ${ }^{12}$.

\author{
Exemplo 1 \\ 13. JAN: Où vous êtes nés? \\ 14. MIC: Ahhh [...] Je suis née à Maceió, ... é [...] Alagoas.
}

Exemplo 2

63. JAN: Ok. Quelle est l'entreprise où vous êtes resté plus de temps?

64. MIC: Ah [...] Onze mois à Planetec et puis qua, six mois, je pense, à API.

\title{
Exemplo 3
}

217. JAN: Est-ce que tu peux me raconter un événement de ta vie d'enfance?

218. MIC: Hum [...] Quelque chose? Quelque chose spéciale?

Dos dizeres acima, destacamos as expressões "Où vous êtes nés?”, “(...) où vous êtes resté plus de temps?” e “ (...) tu peux me raconter ta vie d'enfance?”. Para um falante de francês como língua estrangeira, talvez tais expressões soariam provavelmente corretas. No entanto, para um francófono nativo, tais dizeres soariam estranhos à orelha, ainda que, talvez, não incorretos. De fato, em língua francesa, espera-se, por exemplo, que, com a utilização de pronomes interrogativos, haja a inversão do sujeito e do verbo, o que resultaria na frase “Où êtes-vous nés?”. Já

\footnotetext{
${ }^{11}$ Em português, ter.

${ }^{12} \mathrm{O}$ contexto da produção dos dados e as etapas da pesquisa podem ser encontradas em GOMES, J. N. O enunciador em língua estrangeira: uma constituição possível? Universidade Federal do Rio Grande do Sul: Trabalho de Conclusão de Curso, (2011).
} 
sobre a expressão "rester plus de temps", um francófono diria "rester plus longtemps". E, finalmente, para o dizer "raconter ta vie d'enfance", a forma comumente veiculada em francês seria "raconter ton enfance". Ora, a mescla entre francês e português operada nos dizeres de JAN parece-nos evidente: ao utilizar a ordem pronome interrogativo + sujeito + verbo, a falante reproduz uma sintaxe própria à sua língua materna, o português; a mesma presença ocorre com as expressões "plus de temps" e "vie d'enfance", que se referem claramente a expressões do português brasileiro "mais tempo" e "vida de criança".

Ao constatarmos a presença da língua materna na produção de uma falante de nível avançado da língua francesa e, ao mesmo tempo, a total comunicabilidade de seus dizeres, parece-nos necessário, neste momento, colocar em suspenso a noção de erro na expressão em língua estrangeira. De fato, além de produzir formas significantes em francês - e de fazê-lo utilizando, por vezes, sentidos de sua língua materna - a falante não deixa, em momento algum, de situar-se no sistema linguístico alvo, o francês. Além disso, repetimos, as formas produzidas não nascem ex nihilo, mas, ao contrário, compõem o sistema linguístico de que dispõe. Assim, cabe perguntar-nos, neste ponto, quais os procedimentos linguísticos que permitem a criação de tais formas, que são, a um só tempo, inéditas na língua falada e perfeitamente significativas.

Ainda uma vez, recorreremos às contribuições de Ferdinand de Saussure acerca do que considera o mecanismo primordial dos sistemas linguísticos, a analogia. $\mathrm{O}$ pensador suíço definiu o conceito como a "substância mais clara da linguagem"13 (SAUSSURE, 2002: 141), caracterizado pela produção de formas significantes, feitas em um ato de fala, através da reunião de um certo número de elementos emprestados a diversas séries associativas. É por via deste procedimento, por exemplo, que a palavra imexível, pode ser criada: o falante de português brasileiro compreende o prefixo i- (in-, ir-) como uma unidade significante da língua (neste caso, de negação) e o associa a formas derivadas de verbo com sufixo -vel (mexer, mexível). Ora, sendo tal procedimento "a substância mais clara da linguagem”, e, ocorrendo em falantes de língua materna, por que não ocorreria em falantes de línguas estrangeiras? E, ainda: por que tais formas seriam incorretas se advém das formas mesmas presentes e na língua?

De fato, Saussure não somente define analogia como um fenômeno que se produz na língua falada, como também caracteriza esse fenômeno pelas construções que ele permite produzir e pelos empréstimos que efetua. Isto é, se trata de um mecanismo que depende das duas dimensões da língua, ou seja, do sistema virtual, a língua, e de sua representação no sistema material, o da fala. Esse procedimento analógico é, segundo o linguista genebrino, a condição para que uma língua

\footnotetext{
${ }^{13}$ A passagem completa é a seguinte: "para que não haja nenhum mal-entendido sobre o valor que atribuímos a esses fatos: não são fatos excepcionais e anedóticos, não são curiosidades ou anomalias, mas a substância mais clara da linguagem" (SAUSSURE, 2002: 141).
} 
evolua, mude e possa ser falada e, já que, com a analogia, há sempre um processo de criação, uma "transformação inteligente" (SAUSSURE, 2002: 139).

Não é, portanto, demais esperar que tais criações ocorram segundo o inventário linguístico do falante, que compõe tanto do primeiro sistema de que se apropriou quanto dos demais que conhece. A nosso ver, trata-se essencialmente de um processo de apropriação no qual o falante se apropria da língua alvo e efetua, por um mecanismo que é próprio à língua, a criação de um novo termo, coerente com os sistemas que conhece.

Em Didática de línguas, a situação linguística de MIC e de JAN seria, talvez, considerada interlíngua - segundo as palavras de Christian Puren (apud VOGEL, 1995) -, já que ela é "contraditória", apresenta "conflitos de hipóteses opostas" e "toma emprestado tanto do sistema da língua materna quanto do da língua aprendida" (SAUSSURE, 1995: 71-72). Trata-se, portanto, de uma rede conceitual que parece caracterizar a presença da língua materna como nociva à expressão em língua estrangeira. Além disso, tais conceitos desembocam na noção de erro, isto é, produções que não reproduzem o funcionamento normatizado da língua (CUQ, 2003: 86).

A teoria saussuriana nos propõe um conceito que pode auxiliar-nos nesta forma alternativa de olhar para o que é, até hoje, considerado erro em língua estrangeira e no que, em Didática de línguas, é tratado como interlíngua: trata-se da arbitrariedade do signo. Segundo Saussure, há massas indistintas de sons que podem ser atreladas a massas indistintas de significação; este é o princípio fundamental que rege as unidades componentes de uma língua. A diversidade de idiomas existentes no mundo é um bom exemplo. Em português, o som [o] é um fonema da língua e, além disso, pode significar uma interjeição para chamar alguém - "ô, fulano". Em francês, tal som quer dizer água. Em árabe, em polonês ou em romeno, este fonema pode não existir ou ter valores completamente distintos daqueles em português e em francês. Ao aceitarmos a premissa saussuriana do arbitrário do signo linguístico, parece-nos ser possível, ainda uma vez, colocar em questão a noção de erro. De fato, sendo o erro, de acordo com CUQ (2003), uma questão de normatividade e, sendo o signo linguístico, uma questão de associação de sons previstos em uma comunidade linguística e de ideias, a capacidade significante de uma forma parece depender, principalmente, do respeito a certa regularidade e às oposições que o sistema demanda. Assim, se um sistema linguístico reconhece oposições entre [u] e [y], é, portanto, mister que o falante efetue em alguma medida tais negatividades fonêmicas, caso contrário, em francês, poderá dizer a palavra "todo" ([tu]) ao invés do pronome "tu" $([t y])^{14}$, por exemplo. No entanto, o sistema francês não é somente composto desta oposição e, ao conseguir produzir outras, o falante já se situa nesse sistema, ainda que, talvez, fragilmente. Com efeito, enquanto a noção de erro parece concernir

\footnotetext{
${ }^{14}$ Respectivamente, tout e tu.
} 
substancialmente um ideal normativo de língua ${ }^{15}$, a língua enquanto fala é de sobremaneira uma espécie de negociação entre a orelha daquele que escuta e a boca daquele que fala, levadas em conta as condições do sistema linguístico alvo. O código escrito merece, obviamente, outras análises, mas quando tratamos de expressão oral, parece-nos que o critério para a comunicabilidade deva ser menos atingir formas gramaticais (normativas), que o sucesso em se situar, ainda que com hesitação, no sistema linguístico alvo.

E com esta questão, chegamos à noção de apropriação. Saussure, ao tratar da língua, fala da constituição do "tesouro interior que constitui a língua de cada indivíduo" (Saussure, 1996: 143). De fato, basta dialogarmos com um vizinho para dar-nos conta de diferenças no modo de falar, que vai desde a forma de pronunciar as palavras até a diferença de significação que a elas atribuímos. A citação do linguista suíço parece, então, ser no sentido da singularidade que compõe o sistema linguístico de cada falante. Singularidade, esta, constituída pela relação entre falante e massa falante que rodeou a criança no momento da apropriação de sua primeira língua e que rodeia constantemente o indivíduo a cada ato de fala. Ora, o processo de entrada de contato com línguas não maternas passa, principalmente, pelo contato com demais falantes dessa língua alvo.

Além da singularidade que marca cada "tesouro interior", é possível, também, explorar, na afirmação de Saussure, ainda uma outra característica: aquela de um indivíduo que já é falante de uma primeira língua. Assim, a entrada em contato com novos sistemas linguísticos passa, necessariamente, por este primeiro sistema. De fato, na medida em que é impossível deixar de lado nossa língua materna, toda relação com outro sistema linguístico ocorre através e apesar de nossa língua materna. E é nesse âmbito que consideramos a tomada de contato com línguas estrangeiras um processo marcado pela apropriação, isto é, pelo tornar próprio um sistema falado por terceiros. Não é de se admirar, portanto, que esse tornar próprio apresente traços da primeira língua que permitiu ao sujeito falar.

Assim, erro, analogia e apropriação são manifestações de um mesmo fenômeno, aquele de um falante que, fundado sujeito em uma primeira língua, entra em contato com uma outra língua, em princípio, estrangeira. $\mathrm{O}$ que se considera erro é, portanto, um produto necessário da fronteira entre línguas e da tentativa constante de se situar em um novo sistema linguístico.

Um sincero obrigada a Luiza Milano e a Aline Stawinski pela escuta, pela leitura, pelas trocas, e pelas discussões.

\footnotetext{
${ }^{15}$ Por exemplo, é corrente, em língua francesa, a não produção, pelos falantes, daprescrição gramatical do acordo do particípio passado com o objeto direto colocado anteriormente: "la proposition que j'ai faite" (em português, a proposta que eu fiz).
} 
CUQ, Jean-Pierre. Dictionnaire de didactique du français langue étrangère et seconde. Paris: Cle International, 2003.

GOMES, Janaína Nazzari. O enunciador em língua estrangeira: uma constituição possível?. Porto Alegre: Universidade Federal do Rio Grande do Sul. 2011. Disponível em: http://hdl.handle.net/10183/39339.

LARRUY, Marquillo. M., L'interprétation de l'erreur. Paris: CLE International, 2003.

NORMAND, Claudine. Saussure. São Paulo: Estação liberdade, 2009.

SAUSSURE, Ferdinand de. Phonétique, Il manoscritto di Harvard. Padoue: Unipress, 1995.

. Curso de Linguística Geral. São Paulo: 1996, Cultrix.

. Théorie des sonantes, Il manuscritto di Geneva. Padoue : 2002, Unipress.

. Escritos de Linguística Geral, São Paulo: 2002, Cultrix.

PUREN, C. apud VOGEL, Klaus. L'interlangue, la langue de l'apprenant. Toulouse: Presses universitaires de Mirail, 1995. 